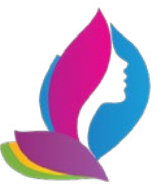 \\ Science Heritage Journal / Galeri Warisan Sains (GWS) \\ Journal Homepage: http://www.razipublishing.com/journals/galeri-warisan-sains-gws https://doi.org/10.26480/gws.01.2017.20.22
}

\section{Tight Repression Of Elastase Strain K Overexpression By Pt7 (A1/04/03) Shuttle Expression System}

Nurul Hazwani Shamsudin ${ }^{1}$, Chee Fah Wong ${ }^{1 *}$, Raja Noor Zaliha Raja Abd. Rahman² and Mohd Shukuri Mohamad Ali ${ }^{2}$

${ }^{1}$ Department of Biology, Faculty of Science and Mathemathics, Universiti Pendidikan Sultan Idris, 35900 Tanjong Malim, Perak, Malaysia ${ }^{2}$ Enzyme and Microbial Technology Research Centre, Faculty of Biotechnology and Biomolecular Sciences, Universiti

Putra Malaysia, 43400 UPM Serdang, Selangor, Malaysia *Corresponding author: cheefah@fsmt.upsi.edu.my

This is an open access article distributed under the Creative Commons Attribution License, which permits unrestricted use, distribution, and reproduction in any medium, provided the original work is properly cited

\section{ARTICLE DETAILS}

Article history:

Received 27 September 2016

Accepted 13 December 2016

Available online 10 January 2017

Keywords:

PT7 (A1/04/03); repression; overexpression; organic solvent tolerant; elastase strain $\mathrm{K}$

\section{ABSTRACT}

The PT7(A1/04/03) is a promoter resulted from construction of 03 and 04 operators into PA1, a promoter derived from coliphage $\mathrm{T} 7$, that evidenced lower the occupancy of the promoter by RNA polymerase and thereby increases the repression factor. A new expression system, pTEL, was successfully constructed via shuttle vector pUCP19 as the backbone as the former carries pre-existing stabilizing fragment (SF) that enables replication of the plasmid in both E. coli and Pseudomonas sp. The leaky lac operon-based promoter found in pUCP19 was subsequently replaced by the PT7 (A1/04/03). Meanwhile, structural gene of the organic solvent tolerant elastase strain $\mathrm{K}$ was used as DNA insert (passenger enzyme) for repression and overexpression studies. The success of pTEL was evidenced by detection of non-significant protein expression level in the absence of IPTG as the inducer, indicating tight regulation possessed by the modified promoter. The addition of IPTG, however, relieved repression and demonstrated overexpression of the elastase strain $\mathrm{K}$ in various strains of E. coli following several optimization studies.

\section{INTRODUCTION}

Detailed knowledge of the biochemistry and structure of individual proteins is fundamental to biomedical research. Many reports have been published demonstrating that certain Pseudomonas proteins cannot be expressed at satisfactory levels in E. coli. Thus, effort to increase the expression of Pseudomonas proteins in an appropriate host is mandatory. The extension of E. coli-based technology to Pseudomonas can be used to overcome such barriers [1]. Many of these advances would not have been possible without the development of genetic and molecular tools including (1) a $1.8 \mathrm{~kb}$ Pstl stabilizing fragment (SF) (ATCC 87110) for replication and maintenance of plasmid in E. coli and (2) the lac and tightly regulated T7(A1/04/03) promoter/repressor systems for control of gene expression [2]. These genetic elements, however, were derived as individual entities and none of them is commercially available. These vectors contain two different origins of replication [3]: (1) rep (pMB1), which is active in E. coli and (2) stabilizing fragment (SF) which derived from pUCP19 to facilitate the cloning, sequencing and expression of genes from various Gram negative bacteria. In 1988, Lanzer and Bujard [4] had discovered that kinetic parameters of RNA polymerase-promoter interaction as well as the position of an operator within the promoter sequence drastically affect the occupancy of the operator by its repressor, which ultimately defines the efficiency of repression. The construction of 03 (a sequence that contained 29 bp wild type operator in a position homologous to Plac) and 04 (sequence that carried a $17 \mathrm{bp}$ core region of the wild type lac operator as spacer between -10 and -33 hexamers of the promoter) into PA01, a promoter derived from coliphage T7, had evidenced in high rate of promoter clearance which lower the occupancy of the promoter by RNA polymerase, thereby increases the repression factor. Therefore, the $\mathrm{T} 7(\mathrm{~A} 1 / 04 / 03)$ promoter is reported to be repressed tightly because it contains two lac operator sites for binding of Lac repressor expressed by laclq [4], but addition of isopropyl- $\beta$-Dthiogalactopyranoside (IPTG) relieves repression and the gene of interest is expressed (2).

2. EXPERIMENTAL

2.1 Source of bacteria and plasmids

Cultures harbouring pUCP19 (ATCC 87100) and pCon2(3) [5] from E coli DH5a and TOP10, respectively, are readily available in the laboratory. Competent cells used in this study were E. coli strain TOP10 (Invitrogen, USA), BL21 (DE3) (Invitrogen, USA) and KRX (Promega, USA). Bacteria were routinely grown in LB broth (Difco, USA) containing ampicillin at the 100 $\mu \mathrm{g} / \mathrm{mL}$ as final concentration.

2.2 Vector Construction

Shuttle vector, pTEL, which harbors a stabilizing fragment (SF) and a tightly regulated T7(A1/04/03) promoter/repressor system was constructed from pUCP19 and pCon2(3). pUCP19 serves as backbone of the construct as the former carries pre-existing SF and other essential elements for screening and plasmid maintenance in E. coli and Pseudomonas sp. An overall flow work of the vector construction is shown in Figure 1. Briefly, a region containing lac promoter was excised from pUCP19 by PstI and Pcil to give rise to pLac-. On the other hand, NdeI was used to digest pCon2(3) to yield a cassette carrying elastase strain $\mathrm{K}$ (which acts as a passenger enzyme) controlled by the modified T7(A1/04/03) promoter, codenamed PstI1500HindIII/T7(A1/04/03). Finally, pTEL was constructed following ligation of the cassette to NdeI pre-digested pLac- by T4 DNA ligase (Fermentas, USA). All DNA fragments and constructs were analyzed using $1 \%$ agarose gel electrophoresis and purified by Gel Extraction Kit (Qiagen, USA) according to manufacturer's instructions. Bacterial transformation of pTEL into E. coli TOP10, BL21 (DE3) and KRX was carried out according to standard protocols as stated elsewhere. The transformed bacteria were then screened on skim milk agar supplemented with ampicillin $(100 \mu \mathrm{g} /$ $\mathrm{mL}$ ) for protease expression which indicated by the formation of clearing zones around the colonies.

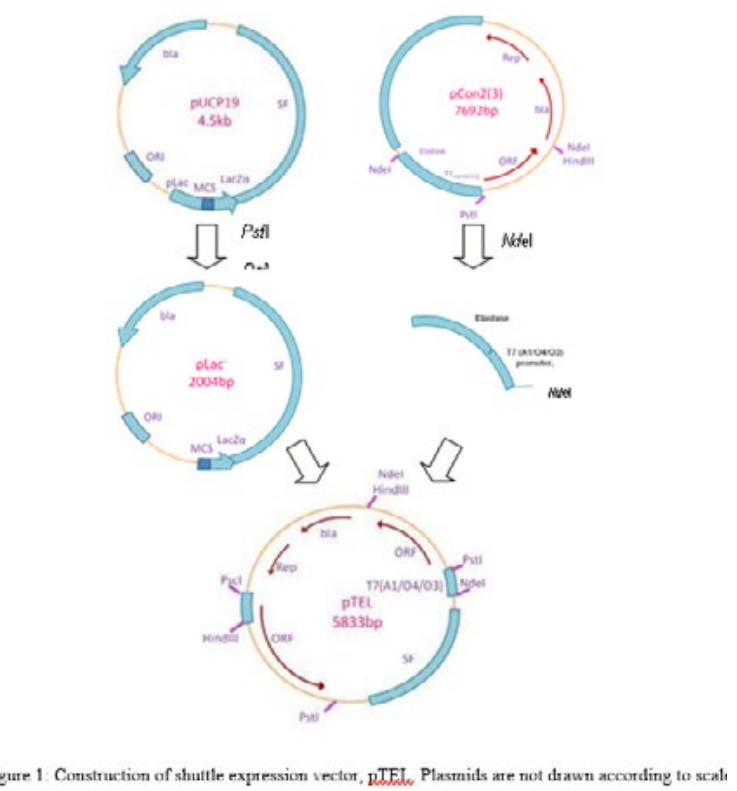

2.3 Expression of Recombinant pTEL by Strains of E. coli

Cultures derived from colonies harbouring empty vectors and recombinant plasmids were inoculated in $10 \mathrm{~mL} \mathrm{LB}$ broth with ampicillin overnight at $37^{\circ} \mathrm{C}$. 
Subsequently, $1.0 \mathrm{~mL}$ of the culture was transferred to $50 \mathrm{~mL}$ LB medium and was shaked at $250 \mathrm{rpm}$ at $37^{\circ} \mathrm{C}$ until optical density at $600 \mathrm{~nm}($ OD $600 \mathrm{~nm})$ reached 0.5 . Induction was carried out by addition of $1.0 \mathrm{mM}$ IPTG. Cells was withdrawn $6 \mathrm{~h}$ after induction for quantification of its expression level. 2.4 Assay of Proteolytic Activity

Proteolytic activity was determined by triplicate using the azocasein methods describe by Tomerelli et al. [6] with minor modification. The substrate, azocasein $(0.5 \%, 1 \mathrm{~mL})$ was pre-incubate at $40{ }^{\circ} \mathrm{C}$ for $5 \mathrm{~min}$. The reaction was started by addition of $100 \mu \mathrm{L}$ enzyme. The reaction mixture was then incubated at $37^{\circ} \mathrm{C}$ for $30 \mathrm{~min}$ and terminated by the addition of $100 \mu \mathrm{L}$ trichloroacetic acid (TCA) $(10 \% \mathrm{w} / \mathrm{v})$. This mixture was incubated at $37{ }^{\circ} \mathrm{C}$ for $30 \mathrm{~min}$, followed by centrifugation at $13000 \mathrm{x}$ g for $10 \mathrm{~min}$. Supernatant of approximately $100 \mu \mathrm{L}$ was harvested, followed by addition of 1.0 $\mathrm{M} \mathrm{NaOH}$ to yield a yellow-orange colour. The absorbance of the coloured mixture was measured at $600 \mathrm{~nm}(\mathrm{~A} 600 \mathrm{~nm})$. A 'blank' was prepared by the same procedure where the TCA was added at zero time and the azocasein after the 10 min incubation.

2.5 Optimization of Elastase Strain K Expression

An overnight culture of recombinant plasmid $(1 \% \mathrm{v} / \mathrm{v})$ was inoculated into $50 \mathrm{~mL}$ of LB broth in $500 \mathrm{~mL}$ shake flask. The optimization study was conducted based on effect of induction time, IPTG concentrations and induction at $0 D 600 \mathrm{~nm}$. The recombinant culture $(10 \mathrm{~mL})$ was centrifuged at $10000 \mathrm{rpm}$ for $10 \mathrm{~min}$ at $4{ }^{\circ} \mathrm{C}$ and the pellet was subsequently resuspended with an equal volume of Tris- $\mathrm{HCl}(50 \mathrm{mM}, \mathrm{pH} 8.0)$ prior to sonication. The soluble protein was obtained after centrifugation at $10000 \mathrm{rpm}$ for 10 min at $4{ }^{\circ} \mathrm{C}$. Protein samples were subjected to protease assay after each optimization study.

2.5.1 Effect of Induction Time

The recombinant plasmid was induced with $1.0 \mathrm{mM}$ of IPTG at $\mathrm{A600 \textrm {nm }}$ reached about 0.5 . Culture was harvested at every $4 \mathrm{~h}$ after induction ranging from $0-43 \mathrm{~h}$.

2.5.2 Effect of IPTG Concentration

The recombinant construct was induced at various concentrations of IPTG $(0.0,0.1,0.2,0.3,0.4$ and $0.5 \mathrm{mM})$ upon A600nm reached about 0.5. Cells were harvested after $16 \mathrm{~h}$ of incubation at $37^{\circ} \mathrm{C}$.

2.5.3 Effect of OD600nm

The recombinant plasmid was induced at different $0 D 600 \mathrm{~nm}$ ranging from 0-1 at 0.25 intervals. Bacterial cells were then induced and incubated according to optimized conditions as mentioned in Section 2.5.1 and 2.5.2.

\section{RESULTS AND DISCUSSION}

\subsection{Construction of pTEL}

In order to confirm the presence of insert in the pUCP19 expression vector PCR was done using Forward M13 and Reverse M13 as universal primers and recombinant plasmid as the template. From the analysis, PCR product of $1.5 \mathrm{~kb}$ was detected (Figure 2(A)). Meanwhile, pCon2(3) releases the PstI1500HindIII/T7(A1/04/O3) following digestion with NdeI (Figure 2 (B)).

\subsection{Expression of Recombinant pTEL by Strains of E. coli}

Referring to Figure 4, E. coli TOP10 showed the highest elastinolytic activity at $127.556 \mathrm{U} / \mathrm{mL}$. This was followed by E. coli BL21 (DE3) and KRX with activity at 94.444 and $91.898 \mathrm{U} / \mathrm{mL}$, respectively. The highest proteolytic activity demonstrated by E. coli TOP10 is due to the ability of the strain to produce several mutant strains exhibiting improved expression of heterologous membrane protein by repression of toxic protein expression [7]. On the other hand, E. coli BL21 (DE3) is the most common nonpathogenic host in recombinant expression [8]. However, the deficiency of ompT and Ion in this strain may interfere with isolation of intact recombinant proteins which corresponded with lower activity of the strain in Figure 4. Other contributing factors include toxicity of target proteins resulting in cell death and occurrence of basal expression which may be lethal to host cell [9-12].

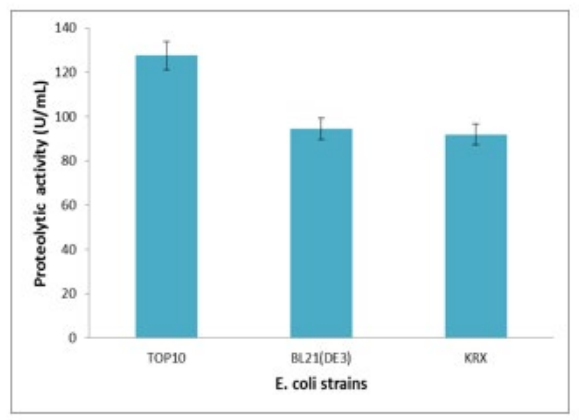

Figure 4 Comparison of proteolytic activity of pTEL, in various strains of $\mathrm{E}$. coli.

\subsection{Optimization of recombinant plasmid}

Expression of the T7(A1/04/O3) promoter is usually induced experimentally by IPTG, which prevents repression of the promoter. However, it does not itself metabolized by the products of the lac operon and so does not have to be continuously replenished in the medium as the cell grows. From Table 1 , the recombinant plasmid was readily expressed within first $4 \mathrm{~h}$ after induction by $1.0 \mathrm{mM}$ of IPTG with activity of $39.556 \mathrm{U} / \mathrm{mL}$. Induction time of as brief as 4 hour was sufficient to produce significant quantities of active protein. Therefore, protein can be expressed and analyzed in less time without the need for overnight induction.

Optimum elastinolytic activity expression was detected at $16 \mathrm{~h}$ after induction with an activity of $198.889 \mathrm{U} / \mathrm{mL}$. Gradual increase of activity is seen from 109.667 to $145.222 \mathrm{U} / \mathrm{mL}$ following induction time of 8 and $12 \mathrm{~h}$, respectively. The proteolytic activities, however, decreased gradually starting from 20 and $24 \mathrm{~h}$ with detection of respective 153.778 and 79.222 $\mathrm{U} / \mathrm{mL}$ (Table 1). An insignificant amount of activity of $5.778 \mathrm{U} / \mathrm{mL}$ was visible at $0 \mathrm{~h}$. Whilst proteolytic activity was not detected in the culture medium.

Table 1 Optimization of elastase strain $\mathrm{K}$ expression.

\begin{tabular}{llll}
\hline Effect & Interval & $\begin{array}{l}\text { Protease } \\
\text { Activity } \\
\text { (U/mL) }\end{array}$ & $\begin{array}{l}\text { Standard } \\
\text { deviation }\end{array}$ \\
\hline & 0 & 5.778 & 0.0027 \\
& 4 & 39.556 & 0.0298 \\
$\begin{array}{l}\text { Induction } \\
\text { time }\end{array}$ & 8 & 109.667 & 0.0728 \\
(h) & 12 & 145.222 & 0.0331 \\
& 16 & 198.889 & 0.0311 \\
& 20 & 153.778 & 0.0273 \\
& 24 & 79.222 & 0.0322 \\
\hline IPTG & 0.0 & 31.556 & 0.0194 \\
concentration & 0.4 & 61.444 & 0.0850 \\
(m) & 0.6 & 110.556 & 0.0162 \\
& 0.8 & 94.333 & 0.0065 \\
& 1.0 & 35.889 & 0.0098 \\
\hline $\begin{array}{l}\text { Induction } \\
\text { optical } \\
\text { density at 600 }\end{array}$ & 0.00 & 36.222 & 0.17080 \\
& 0.25 & 68.667 & 0.13700 \\
\hline
\end{tabular}


The IPTG used in this study compromises two important advantages which are its uptake is not dependent on LacY permease but it diffuse passively through the inner membrane and it is not cleaved $\beta$-galactosidase. Protease activity was detected at all tested concentrations of IPTG with the optimum level achieved at $142.889 \mathrm{U} / \mathrm{mL}$, after $16 \mathrm{~h}$ of induction by $0.6 \mathrm{mM}$ IPTG. Under the similar condition, an IPTG concentration of 0.2 and $0.4 \mathrm{mM}$ also displayed a significantly high elastinolytic activity of 61.444 and 110.556 $\mathrm{U} / \mathrm{mL}$ respectively. Gradual decreases of activities were observed after the IPTG concentrations increase to 0.8 and $1.0 \mathrm{mM}$ with activity of 94.333 and $35.889 \mathrm{U} / \mathrm{mL}$, respectively.

High inducer concentrations may result in formation of inclusion bodies, which initiated by misfolding commonly accumulated in the cells upon the overproduction of gene products [13], as seen in Table 1. At such concentrations, most of the surviving cells will lose the expression plasmids [14] and high levels of induction are known to kill cells that carry a multicopy plasmid with T7 promoter, even if the target protein is non-toxic to hosts [11]. It is well documented that production of soluble proteins is promoted by culturing at reduced temperatures, selection of different $\mathrm{E}$. coli strains, substitution of selected amino acid residues, and co-production of chaperone and alteration of the $\mathrm{pH}$ of culture medium [14]. Alternatively, low concentrations of inducer, for instance lactose $(0.005 \%)$, will exhibit a high level of expression but the culture density, viability and maintenance of plasmid were all comparable to what was found in the absence of added lactose [15]. While increasing the amount of lactose ( $>0.05 \%)$, the protein expression remained high with density of saturated culture and viability had decreased substantially. In addition, cells induced using very low IPTG have more metabolic control over the toxic effect than those induced with standard IPTG concentrations [16]. According to Ramirez et al. (1994) [17], low IPTG concentrations may result in low recombinant protein yields, whereas expensive IPTG added in excess can result in an important economic loss or in toxic effects, including reduced cell growth and recombinant protein concentration.

Differences in lag time or growth rate typically generate a situation where different cultures will be ready for induction at different times [15]. Table 1 clearly showed the optimum expression level of $186.778 \mathrm{U} / \mathrm{mL}$ was only reached at an induction 0D600nm of 1.00. Induction 0D600nm of $0.25,0.50$ and 0.75 , in contrast gradually increased from 68.667 to 131.111 and finally attained $149.778 \mathrm{U} / \mathrm{mL}$, respectively. This is due to the induction at high cell density has resulted in the function of soluble proteins and high efficiency of fractionation [18].

Furthermore, a non-significant expression level of $36.222 \mathrm{U} / \mathrm{mL}$ was detected at $0 D 600 \mathrm{~nm}$ of 0.00 as IPTG induction at low cell density resulted in the formation of inclusion bodies [18]. Studier [15] had showed that protein expression could not be detected at early log phase stage but rapid, high level production was monitored as the growth rate approaching to saturation, similar to timing observes by Grossman et al. [19]. A pro-longed incubation of $15 \mathrm{~h}$ had dedicated to further increases in culture density due to overgrowth of cells that had lost plasmid, thus resulted in reduction of protein expression [15].

\section{CONCLUSIONS}

The construction of shuttle expression vector, pTEL, confers new alternative for protein overexpression in E. coli and promises potential application in Pseudomonas as a new host cell. The presence of dual repression genetic elements in pTEL, the 03 and 04, and the tightly controlled PT7 promoter has further repressed basal expression in tested bacterial strain and thus countered all detrimental effects caused by the basal expression, as discussed earlier. Additionally, the PT7(A1/04/03) has drove the overexpression of active protein, as evidenced by high proteolytic activities under optimized conditions. Our recent modification of the pTEL has demonstrated that this construct is able to replicate independently with high copy number and stably integrated into genome of Pseudomonas (data not shown), strongly suggesting function of the SF region for plasmid maintenance not only in Pseudomonas but also extended to its related genus, for instance Burkholderia sp. and Klebsiella sp.

Acknowledgement

We would like to thank the Ministry of Science, Technology and Innovation
(MOSTI), Malaysia, for the research funding under E-ScienceFund (Project number: 02-01-11-SF0015).

\section{References}

[1] Schweizer, H. P. 2001. Vectors to express foreign genes and techniques to monitor gene expression of Pseudomonas. Current Opinion in Biotechnology. 12: 439-445.

[2] Suh, S., Silo-Suh, L. A., and Ohman, D. E. 2004. Development of

tools for genetic manipulation of Pseudomonas aeruginosa. Journal of Microbiological Methods. 58: 203-212.

[3] Schumann, W. 2008. Escherichia coli cloning and expression vectors. ln: Plasmids Current Research and Future Trends, (ed.) Lipps, G., Caister Academic press, Norfolk, U. K. pp: 1-25.

[4] Lanzer, M., and Bujard, H. 1988. Promoters largely determine the efficiency of repressor action. Proceedings of the National Academy of Sciences of the United States of America, 85: 8973-8977.

[5] C. F.Wong (2010). Overexpression and characterization of organic solvent-tolerant elastase strain $\mathrm{K}$ in newly constructed vectors (Doctoral dissertation). Universiti Putra Malaysia (UPM), Serdang, Malaysia.

[6] Tomarelli, R. M., Charney, J. and Harding, M. L. 1949. The use of azoalbumin as a substrate in the colorimetric determination of peptic and tryptic activity. Journal Laboratory Clinical Medical. 34: 428-433.

[7] Elizabeth, M. G., Anni, Z., Gabriella, B., Hye-Yeon, K., Michael, A. B., Len, M. S., Robert, K., Nakamoto and James, U. B. 2009. Genetic selection system for improving recombinant membrane protein expression in E. coli. Protein Science. 18(2): 372-383.

[8] Chart, H., Smith, H.R., La Ragione, R.M., Woodward MJ, 2000. An investigation into the pathogenic properties of Escherichia coli strains BLR, BL21, DH5alpha and EQ1. Journal Application Microbiology. 89: 1048-1058. [9] Dubendorff, J. W., and Studier, F. W. 1991. Controlling basal expression in an inducible T7 expression system by blocking the target T7 promoter with lac repressor. Journal Molecular Biology. 219: 45-59

[10] Pan, S. H., and Malcolm, B. A. 2000. Reduced background expression and improved plasmid stability with pET vectors in BL21 (DE3). Biotechniques. 29: 1234-1238.

[11] Studier, F. W. 1991. Use of bacteriophage T7 lysozyme to improve an inducible T7 expression system. Journal Molecular Biology. 219: 37-44.

[12] Schumann, W. 2008. Escherichia coli cloning and expression vectors. In: Plasmids Current Research and Future Trends, (ed.) Lipps, G., Caister Academic press, Norfolk, U. K. pp: 1-25.

[13] Rahman, R. N. Z. R. A., Leow. T. C., Basri, M., and Salleh, A. B. 2005 Secretory expression of thermostable T1 lipase through bacteriocin release protein. Protein Expression and Purifivation. 40: 411-416.

[14] Makrides, S. C.1996. Strategies for achieving high level expression of genes in Escherichia coli. Microbiology Revision. 60: 512-538.

[15] Studier, F. W. 2005. Protein production by auto-induction in highdensity shaking cultures. Protein Expression and Purification. 41: 207-234.

[16] Saida, F., Uzan, M., Odaert, B., and Bontems, F. 2006. Expression of highly toxic genes in E.coli specials trategies and genetic tools. Current Protein and Peptide Science. 7: 47-56.

[17] Ramirez, O. T., Zamora, R., Espinosa, G., Merino, E., Bolivar, F. and Quintero, R. 1994. Kinetic study of penicillin acylase production by recombinant Escherichia coli in batch Cultures. Process Biochemistry. 29: 197-206.

[18] Choi, J. H., Jeong, K. J., Kim, S. c., and Lee, S. Y. 2000. Efficient secretory production of alkaline phosphatase by high cell density culture of recombinant Escherichia coli using the Bacillus sp. endoxylanase signal sequence. Applied Microbiology and Biotechnology. 53: 640-645.

[19] Grossman, T. H., Kawasaki, E. S., Punreddy, S. R., and Osburne, M. S. 1998. Spontaneous c-AMP dependent derepression of gene expression in stationary phase play role in recombinant expression instability. Gene. 209: 95-103. 